\title{
Effect of the Tube Material on the Thermal Performance of a Ranque-Hilsch Vortex Tube
}

\author{
Amany A. A. Mohamed ${ }^{1}$, Hussein M. Maghrabie ${ }^{2 *}$, M. Attalla ${ }^{3}$
}

\begin{abstract}
The vortex tube is very simple thermo-fluidic apparatus which generates low temperature and high temperature air streams. The inlet fluid is tangentially compressed into the inlet nozzles of vortex tube. The purpose of the submitted research is to discuss the thermal characteristics of vortex tube with aluminum material by changing some of working parameters which include pressure of the entry air and cold mass ratio. The values of inlet air pressure include $(4,6,8,10 \mathrm{bar})$ as well as the values of cold mass ratio includes values from 0.4 to 0.9 by increment of 0.1. In the present investigation the vortex tube is manufactured from aluminum material and the entire generator is made of polymer material which allow more lightness in weight of construction of vortex tube. The experimental outputs reveal that at $20{ }^{\circ} \mathrm{C}$ of inlet air temperate with 10 bar inlet air pressure the optimum hot air temperature reached $125{ }^{\circ} \mathrm{C}$ and the optimum cold air temperature maintained $-14{ }^{\circ} \mathrm{C}$ at the same operation conditions. Moreover, the results of the present study were compared with previous published research work. Consequently, the outcomes of this study exhibited that the vortex tube with aluminum material enhanced the hot temperature separation by $70 \%$ as well as more highly cold temperature separation closely to other empirical outputs.
\end{abstract}

Keywords: Vortex tube; Temperature separation; Tube material; COP; Cold mass ratio

\author{
Nomenclature \\ $\Delta T \quad$ temperature drop $\left({ }^{\circ} \mathrm{C}\right)$ \\ $C_{p} \quad$ specific heat at constant pressure $(\mathrm{kJ} / \mathrm{kg} \mathrm{K})$ \\ CR cold mass ratio (--) \\ $D \quad$ vortex tube inner diameter $(\mathrm{mm})$ \\ $L \quad$ tube length (mm)
}

\footnotetext{
Received: 15 December 2020/ Accepted: 26 December 2020 *Corresponding Author: Hussein M. Maghrabie, E-mail: Hussein_mag@eng.svu.edu.eg

1, 2, 3. Department of Mechanical Engineering, Faculty of Engineering, University of South Valley, 83523 Qena, Egypt
}

$\begin{array}{ll}\dot{m} & \text { mass flow rate }(\mathrm{kg} / \mathrm{s}) \\ P & \text { inlet pressure }(\mathrm{bar}) \\ R & \text { gas constant }(\mathrm{kJ} / \mathrm{kg} \mathrm{K}) \\ T & \text { temperature }\left({ }^{\circ} \mathrm{C}\right)\end{array}$

\section{Subscript}

$\begin{array}{ll}\text { a } & \text { atmosphere } \\ \text { c } & \text { cold air } \\ \text { h } & \text { hot air } \\ \text { i } & \text { inlet air }\end{array}$

\begin{abstract}
Abbreviations
COP Coefficient of Performance (--)

RHVT Ranque-Hilsch Vortex Tube

VT Vortex Tube
\end{abstract}

\section{Introduction}

The Ranque-Hilsch vortex tube (RHVT) is a mechanical equipment that could be used in cooling applications or in heating application; as it could separate the inlet compressed gas into two different temperature streams one is hot and the second stream is cold. The phenomenon of temperature separation was firstly discovered by French physicist engineer Georges Ranque in 1933 [1, 2]. Accordingly, practical and theoretical researches were continued with the purpose of enhancing the efficiency of the vortex tube (VT) by German engineer Rudolf Hilsch [3]. Generally, there are two different designs of RHVT; the major type is known as counter-flow form and the second is known as uni-flow form. Figs. 1a and $\mathbf{b}$, respectively are shown the two constructions in details [4].

The counter-flow VT has one inlet and two exits at the opposite directions, while the uni-flow type has one inlet and two exits at only one end. Generally, the counter-flow VT is characterized by high efficiency in temperature separation compared to uni-flow type, because in the uni- flow type it is noted that the hot flow is exposed to mix with the cold flow at the near exits of two streams; so, there is no doubt that it affects negatively on its efficiency. 
In the recent years, there are several explanations were published to investigate the performance of the VT. Westley [5] optimized the main design format of the VT and worked on changing some of operating and geometric parameters which achieved maximum values of cold temperature difference. Takahama et al [6-9] performed experiments and reported some of formulas which described the energy separation of VT and its relationship with the geometry of VT as they checked in details the geometry of the VT and study how effect number of inlet nozzles on the vortex performance. Valipour et al. [10-11] indicated to the effect of main physical properties of inlet fluid of VT such as its pressure, its temperature and the humidity percent which loaded in air. Additionally, they indicated to the effect of the geometric properties of VT on the cooling performance such as VT inner diameter and tube length, dimensions of access nozzle and diameter of the cold end. As well, they studied how the cooling performance could be affected with angle of bending of hot tube. Singh et al [12] examined experimentally the action of change the cold mass ratio, nozzle design, as well as the ratios of length to diameter of the tube on the cooling performance of VT. It was concluded that the design of nozzle had more effect on the splitting temperature of VT and when the ratio of the tube length to its diameter (L/D) is increased by about $45-55 \%$ had unnoticeable effect on the thermal performance. Behera et al [13] optimized the temperature difference of hot flow and cold flow based on the ratios of length to diameter of the VT. Attalla et al [14] investigated experimentally the influence of inlet nozzles number contains in the vortex generator on the performance of VT. The results indicated that the generators which have 3, 4 and 6 nozzles produced highest performance. Kaya et al [15] studied empirically the impact of design properties of the entire generator of VT such as nozzles number and generator material. It was found that the best generator which provided the maximum energy separation which has six nozzles and made of aluminum material in the case of two parallel connected configuration of vortex tubes

From the above literature review, it is clear that the splitting temperature separation and the performance of a VT are obviously linked to changing the operation and design parameters. So that many companies starting competing in production models of vortex tubes with different technical specification that make them more efficient. The previous studies were focused to modify the heating and cooling performance of the VT by changing its geometric dimensions as well as the type of material. So, the current study is dedicated to examine the main characteristics of the counter-flow VT manufactured from aluminum material and the entire generator made from polymer material which allowed also more lightness in weight of the VT construction. In the current implementation, the thermal performance of the RHVT under different operating parameters such as the inlet air pressure $\left(P_{i}=4,6,8\right.$, and 10) bar with varying the cold mass ratio $(C R=0.4$ to 0.9$)$ is investigated.

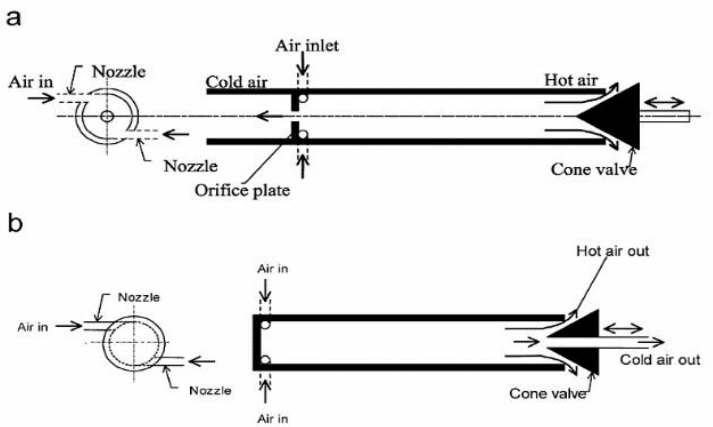

Fig. 1. Basic operation of VT (a) counter-flow (b) uni-flow.

\section{Experimental system and steps of experiments}

The real picture of the examined VT model of RZJ-W025 is shown in Fig. 2. The construction of the vortex system contains mainly from vortex chamber $(D=$ $30 \mathrm{~mm})$, hot tube $\left(L_{h}=113 \mathrm{~mm}, d_{h}=13 \mathrm{~mm}\right)$ and a swirl generator insert into the vortex chamber is made from the polymer material, its diameter having the same value of inner diameter of the vortex chamber. In the current study, theVT is manufactured from aluminum material which distinguished it light in weight about 400 grams and thermal conductivity of aluminum is about $247 \mathrm{~W} / \mathrm{m} \mathrm{K}$ which provides a greater opportunity to transfer heat between vortices of air during its motion without occurring any dissipation of energy. Meanwhile, the entire generator is made from a polymer material which allows also more lightness in weight of construction of the VT. Furthermore, the polymer material has a very low-density property about $1173 \mathrm{~kg} / \mathrm{m}^{3}$ so that the operation of air rotation after entering the vortex chamber becomes faster as it can rotate faster due to its low weight and consequently temperature separation is better performed.

The experimental set-up consists of an air compressor $\left(10 \mathrm{bar}, 0.167 \mathrm{~m}^{3} / \mathrm{min}\right.$ and $\left.7.5 / 10 \mathrm{~kW} / \mathrm{Hp}\right)$, air surge tank, filter to remove impurities from air, dehumidifier 
device, pressure measurement device of Danfoss - Model: AKS-33, temperature measurement device of RTD -
Model: TX251, digital flow meter of Model: LUGY-15 and vortex tube as illustrated in Fig. 3.

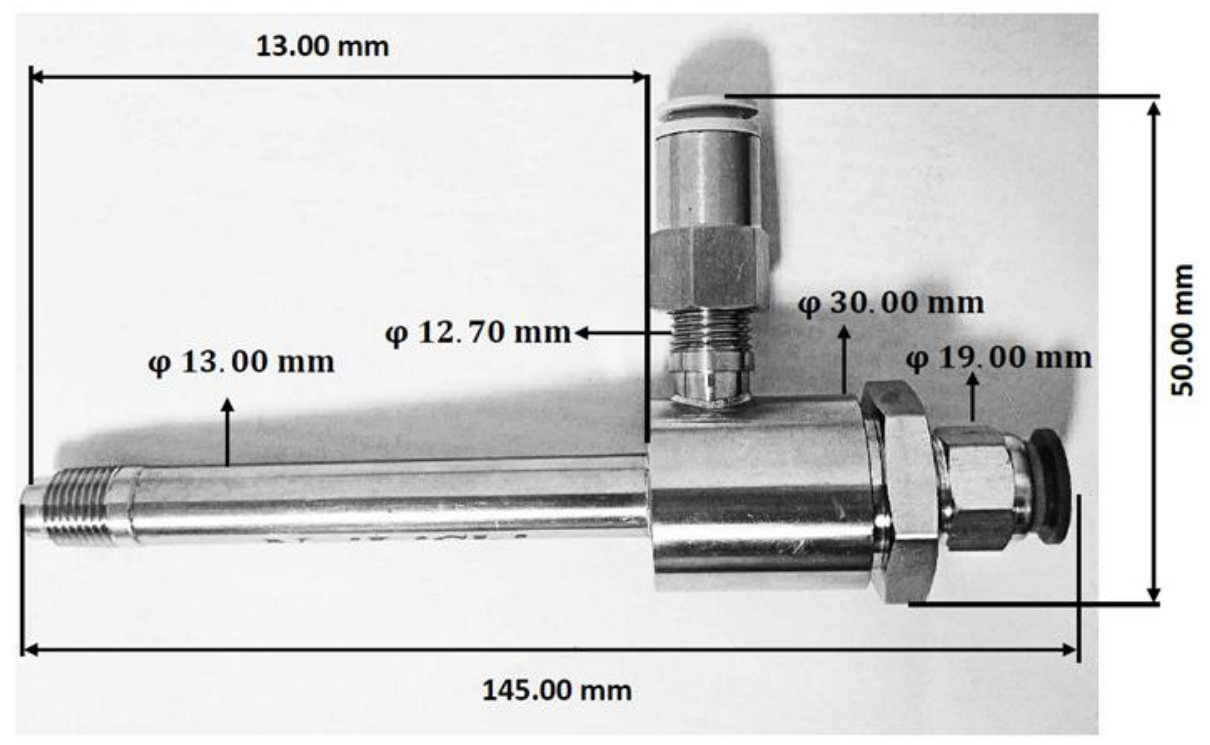

Fig. 2. Real photograph of the examined vortex tube

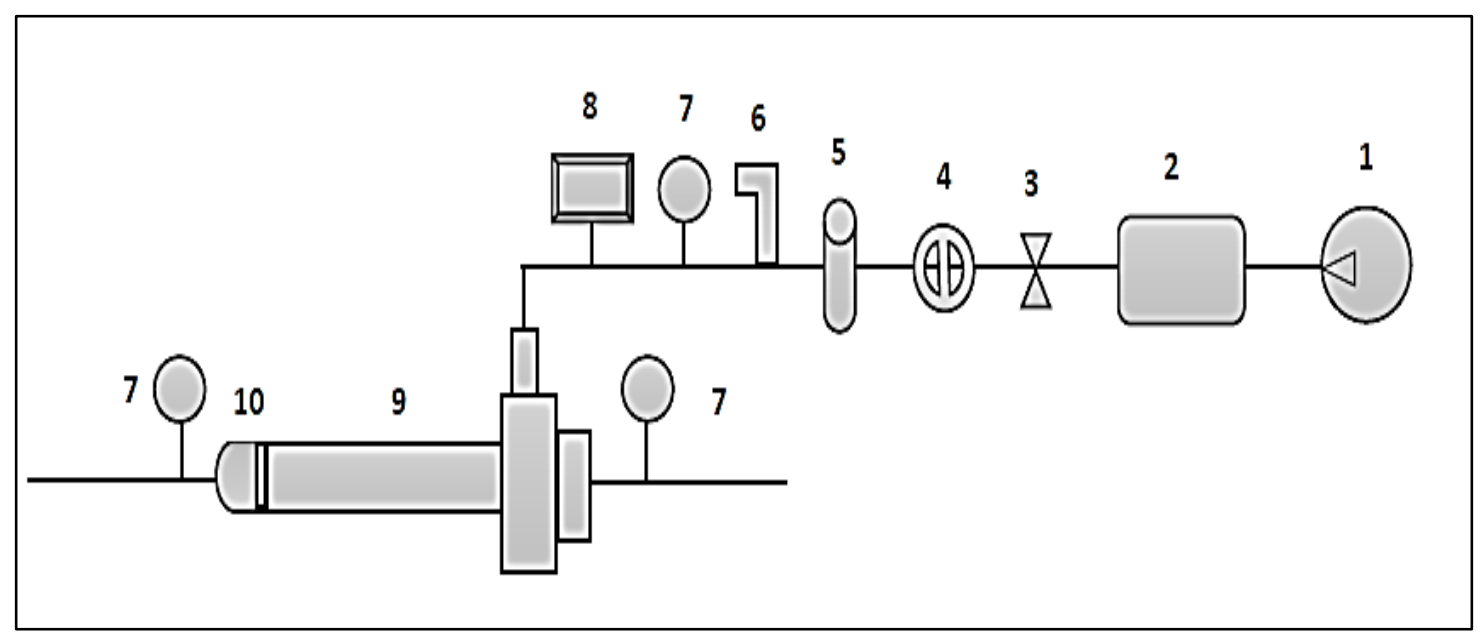

1. Air compressor. 2. Surge tank. 3. Valve of pressure regulator. 4. Filter. 5. Dehumidification device. 6. Pressure measurement device. 7. RTD unit. 8. Digital flow meter. 9. RHVT. 10. Hot control valve.

Fig. 3. Schematic graph of the test rig.

As indicated in the above Fig. 3, the compressor supplies the compressed air with 167 liters per minute of flow rate at 10 bar of pressure. The air pressure during the experiments are adjusted with different values between 4 bar and 10 bar with 2 bar increment, then it passes gradually through the air filter, the dehumidification device, then passes via pressure measurement device as the pres- sure of the air is checked to ensure from the value of pressure which have been already adjusted by pressure regulator valve. Hence, the compressed air is inserted into the VT and permeates into the inlet nozzles where it is rotated with very high speed and as a result of some physical effects the air is split into the high temperature air stream and low temperature air stream. The cold flow 
leaves through the focal core of vortex polymer generator but the hot flow leaves at the opposite exit of the other end of VT. During the current study, the cold mass ratio is changed from 0.4 to 0.9 with an increment of 0.1 and those values could be controlled by opening the hot rotary valve gradually at the extremity part of the hot tube. All temperature measurements at inlet and both exits of VT were measured by thermocouples by RTD units with a precision of $\pm 0.1{ }^{\circ} \mathrm{C}$. Also, the inlet air flow was calibrated by the digital flow meter device with an accuracy of $\pm 0.1 \%$. For each measurement step, the time required to record the results of the pressure and temperature to reach at the steady state operation is about 5 minutes. In this study, the experiments were performed at approximately room temperature of $20^{\circ} \mathrm{C}$.

\section{Data reduction}

In this section, there are some of important terminologies that should be mentioned to discuss the thermal performance of the counter-flow VT.

\subsection{Cold mass ratio (CR)}

The cold mass ratio $(C R)$ is considered the main parameter which gives an indication of energy separation of the vortex tube. The cold mass ratio is the percentage of the mass flow rate of the input compressed air that escaped from the cold orifice end of the VT. It can be calculated from dividing the value of output of cold mass flow rate by the value of the input air mass flow rate. The hot rotary valve which is located at the extremity part of the hot tube can adjust the amount of cold mass ratio. Therefore, the cold mass ratio $(C R)$ is in the range of $0 \leq \mathrm{CR} \leq 1$. The cold mass ratio can be defined as follows:

$$
C R=\frac{\dot{m}_{c}}{\dot{m}_{l}}
$$

where $\dot{m}_{c}$ is the cold flow mass flow rate and $\dot{m}_{l}$ is the inlet flow mass flow rate.

\subsection{Cold air temperature difference $\left(\Delta T_{c}\right)$}

The cold air temperature difference $\left(\Delta T_{c}\right)$ gives an indication of the temperature division inside the VT. It can be calculated by subtracting the cold air temperature from the inlet air temperature:

$$
\Delta T_{c}=T_{i}-T_{c}
$$

where $T_{i}$ is the temperature of the inlet air and $T_{c}$ is the temperature of the cold air.

\subsection{Hot air temperature difference $\left(\Delta T_{h}\right)$}

The hot air temperature difference $\left(\Delta T_{h}\right)$ is calculated by subtracting the inlet air temperature from the hot air temperature:

$$
\Delta T_{h}=T_{h}-T_{i}
$$

where $T_{h}$ is the temperature of the hot air.

In general, the thermal performance of the VT could be expressed by subtracting the value of cold temperature from the value of hot temperature and is symbolized by $(\Delta T)$ which known as the splitting air temperature or the thermal performance as follows [16]:

$$
\Delta T=T_{h}-T_{c}
$$

\subsection{Coefficient of performance $(C O P)$}

The coefficient of performance $\left(\mathrm{COP}_{R}\right)$ of the VT can be defined by taking into account that the VT could be dealing as a refrigerator device or dealing as a heater/heat pump which can be obtained as follows [17]:

$$
\begin{gathered}
C O P_{R}=\frac{\dot{m}_{c}}{\dot{m}_{i}} \frac{c_{p}\left(T_{i}-T_{c}\right)}{\mathrm{R} T_{i} \ln \left(P_{i} / P_{a t m}\right)} \\
C O P_{H P}=\frac{\dot{m}_{h}}{\dot{m}_{i}} \frac{c_{p}\left(T_{h}-T_{i}\right)}{\mathrm{R} T_{i} \ln \left(P_{i} / P_{a t m}\right)}
\end{gathered}
$$

Where $C_{p}$ the specific heat of air and (R) is the general gas constant.

\section{Experimental outputs and discussion}

In the current experimental study, the influence of air inlet pressure and cold mass ratio on the thermal performance of the VT are studied to evaluate the main VT characteristics which distinguishes the examined model of VT with aluminum material.

4.1 Air inlet pressure affection 
The hot outlet temperatures $\left(T_{h}\right)$, and cold outlet temperature $\left(T_{c}\right)$ as a function of air inlet pressure set at the inlet air temperature of about $20^{\circ} \mathrm{C}$ are shown in Figs. 4 and $\mathbf{5}$. It was noted from Fig. $\mathbf{4}$ that the outlet hot temperature increases sharply with changing inlet air pressure by increment of 2 bar for each step. While, the outlet cold temperature decreases with changing inlet air pressure by increment of 2 bar for each step as shown in Fig. 5. This energy separation occurred inside the VT by this way as a result of entering the compressed air to the RHVT with high pressure and with high velocity, resulting higher speed vortices and a momentum heat convection occurred from the central area of air vortices to the outer area of air vortices. This phenomenon exhibits a better separation in temperature, leading to higher energy at the outer radius of the air vortex and a lower energy at the inner radius of the air vortex.

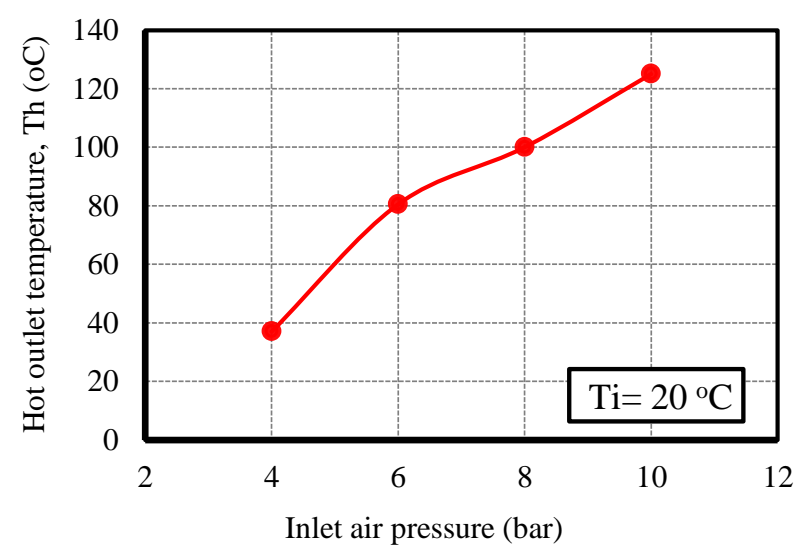

Fig. 4. Hot outlet temperature as a function of inlet air pressure.

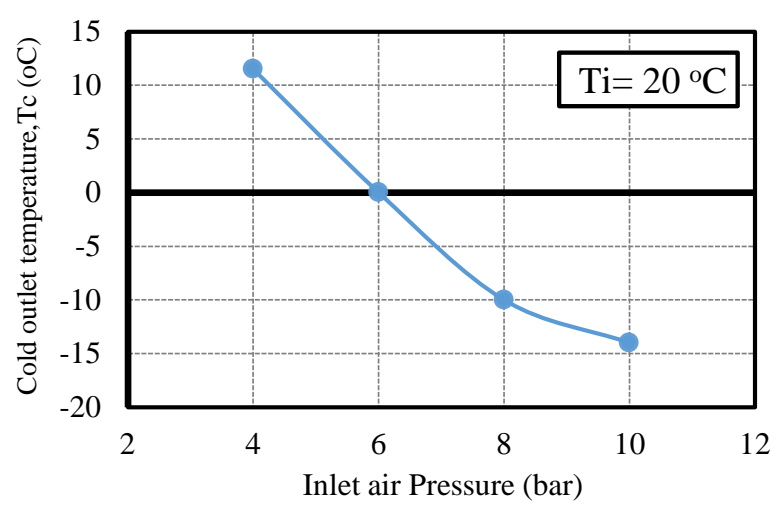

Fig. 5. Cold outlet temperature as a function of inlet air pressure.

4.2 Cold mass ratio affection
Figures 6 and 7 illustrate the effects of the cold mass ratio $(C R)$ on the hot and cold temperature differences $\left(T_{h}-T_{i}\right)$ and $\left(T_{i}-T_{c}\right)$, respectively. These results are obtained at four values of inlet air pressure 4, 6, 8 and 10 bar. The influence of cold mass ratio on the temperature difference of VT at various inlet air pressure was also investigated. It was noted from Fig. 6 when the cold mass ratio increases the hot temperature difference is increased directly. As the case of $C F=0$ indicated that there is no cold flow is applied from the cold end side (with fully open of hot control valve), while the case of $C F=1$ indicated that there is no hot flow is applied from the hot end side (with fully closed of hot control valve). The maximum hot temperature difference is obtained as $100^{\circ} \mathrm{C}$ with 10 bar inlet pressure and at 0.9 cold mass ratio.

Otherwise, it is observed from Fig. 7 that when the cold mass ratio increases the cold temperature difference is decreased for various inlet pressure so that the highest cold temperature difference measured is $40^{\circ} \mathrm{C}$ at the inlet pressure 10 bar and 0.4 cold mass fraction. Additionally, closing the hot rotary valve reduces the flow area of hot flow exit, the reversed flow rate toward the cold flow exit increases, so that the friction and heat contact between the layers of hot flow and cold flow were occurred. Therefore, the heating energy can be emitted from the hot gas stream to cold gas stream as the cold mass ratio increases, which cause a decrease in the cold temperature difference and the opposite of this explanation occurs with hot temperature difference.

The VT is considered as a refrigerating or as a heating device, so that it is necessary to evaluate the outputs of $C O P$. In following part, the COP outputs for both refrigerator and heat pump are obtained in Figs. 8 and 9 as the figures explain the influence of inlet air pressure as a function of cold mass ratio on $C O P$ values. The maximum $C O P$ value in case of refrigerator was determined at 4 bar value of inlet air pressure and equals to 0.52 , while the maximum COP value in case of heat pump was determined at 4 bar value of inlet pressure and equals to 0.35 . In general, the COP of refrigerating and heating decreases as the inlet pressure is increased and the COP for cooling are rising with increasing of the cold mass ratio $(C R)$ while $C O P$ for heating are reducing with increasing of the cold mass ratio $(C R)$. 


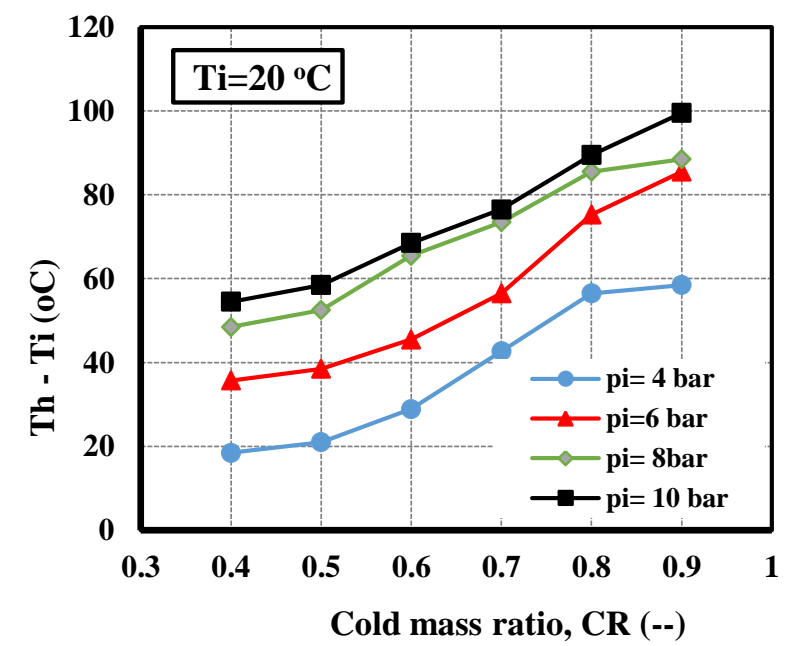

Fig. 6. Hot temperature difference as a function of cold mass ratio at different inlet pressures.

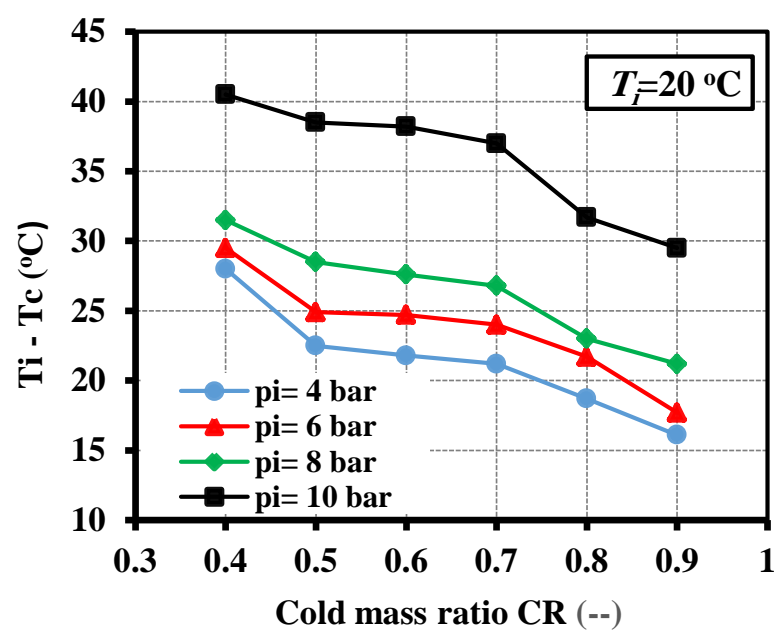

Fig. 7. Cold temperature difference as a function of cold mass ratio at different inlet pressures.

\section{Comparison performance with some of previous researches}

By setting a comparison with some previous researches which have been used vortex and have dimensions almost close to the proposed examined model dimensions of the VT. As indicated from Table 1 there are some of important variables which are collected from previous experimental studies until the current date. The table includes some effective parameters which have an influence

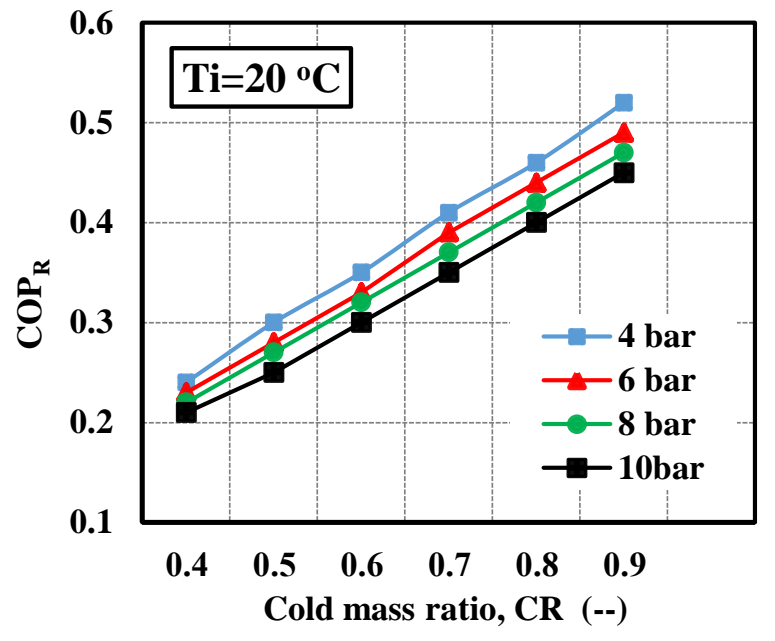

Fig. 8.COP $P_{R}$ as a function of cold mass ratio for $T_{i}=20^{\circ} \mathrm{C}$ and $P_{i}=4,6,8,10$ bar.

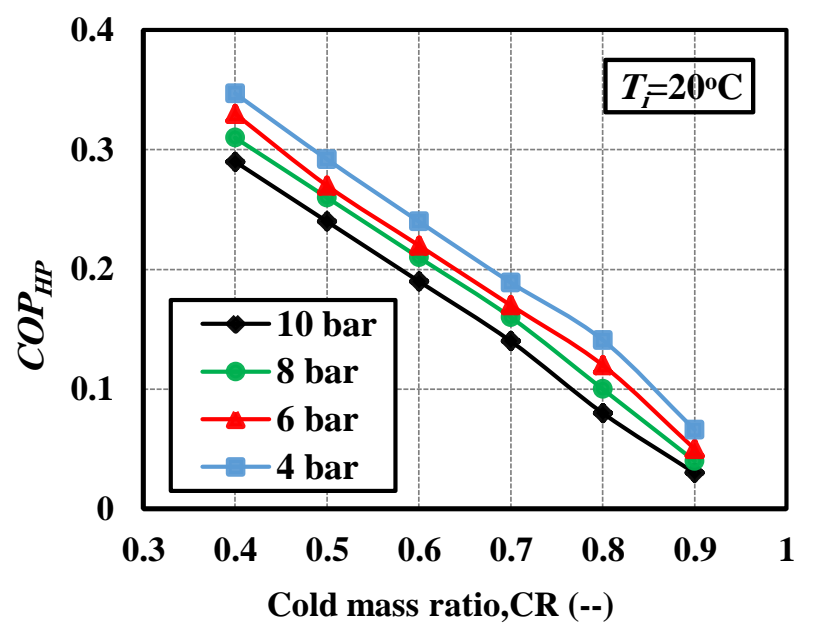

Fig. 9. $C O P_{H P}$ as a function of cold mass ratio for $T_{i}=20^{\circ} \mathrm{C}$ and $P_{i}=4,6,8,10$ bar.

on the temperature separation of vortex tubes such as tube diameter $(D)$, tube length $(L)$, optimum values of cold mass ratio $(C R)$, and inlet pressure $\left(P_{i}\right)$. There are about 8 groups of experimental data are used in comparison with RZJ-W025 model of VT. It is important to take into consideration that the experiments are performed by varying a number of operating or geometric parameters of VT and holding the other parameters are constant. For instance, cold mass ratio is varied by modifying the amount of opening or closing hot rotary valve position, also the length and diameter of VT could be constant or varied in other 
investigations. Therefore, in the above table the optimum conditions of geometric dimensions of the VT and cold mass ratio are recorded.

Figures 10 and 11 showing the fluctuation of the difference respectively with respect to the inlet pressure. It was noted that the proposed model has more hot temperature separation better than the previous studies by $70 \%$ and the tested model have also high acceptable cold temperature separation is more closing to the previous studies.

Table 1 Extraction of some experimental researches of vortex tubes.

\begin{tabular}{c|clcccccc}
\hline $\boldsymbol{R e f}$ & Year & Author $(\boldsymbol{s})$ & $\boldsymbol{D}(\boldsymbol{m m})$ & $\boldsymbol{L}(\boldsymbol{m m})$ & $\boldsymbol{P}_{\boldsymbol{i}}(\boldsymbol{b a r})$ & $\boldsymbol{C F}_{\text {opt }}$ & $\Delta \boldsymbol{T}_{\boldsymbol{h} \text { max }}\left({ }^{\circ} \mathrm{C}\right)$ & $\Delta \boldsymbol{T}_{\boldsymbol{c}, \boldsymbol{m a x}}\left({ }^{\circ} \mathrm{C}\right)$ \\
\hline$[1]$ & 1933 & Ranque & 12 & N.A & 7 & N.A & 38 & 32 \\
{$[18]$} & 1956 & Martynovskii and Alekseev & 9 & 450 & 6 & 0.3 & 16.3 & 38 \\
{$[19]$} & 1968 & Vennos & 41.3 & 1070 & 5.8 & 0.35 & -1 & 13 \\
{$[13]$} & 2005 & Behera et al & 12 & 120 & 5.4 & 0.38 & 26 & 23 \\
{$[20]$} & 2008 & Hamoudi et al & 2 & 100 & 5 & 0.57 & 11.8 & 18.5 \\
{$[21,22]$} & 2011 & Dincer et al & 9 & 135 & 7.3 & 0.2 & 30 & N.A \\
{$[23]$} & 2014 & Liu & 10 & 120 & 6 & 0.9 & 13.5 & 22.5 \\
{$[14]$} & 2017 & Attalla et al & 7.5 & 225 & 6 & 0.9 & 47 & 33 \\
\multicolumn{2}{l}{ Present study (model RZJ-W025) } & 30 & 145 & 8 & 0.9 & 80 & 32 \\
\hline
\end{tabular}

N.A: not available

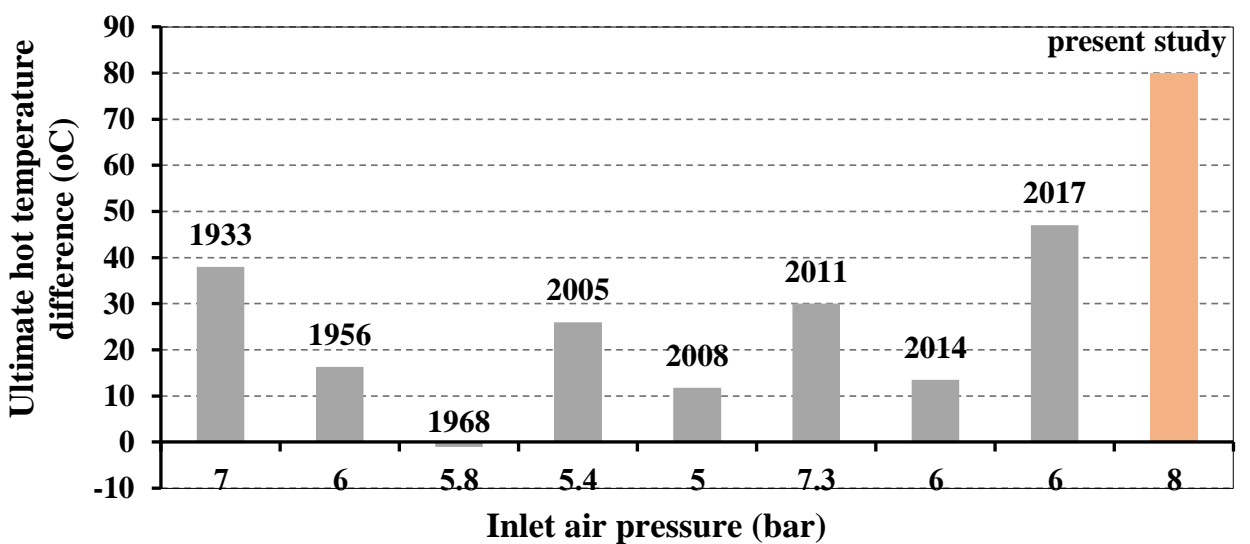

Fig. 10. Ultimate hot temperature difference versus inlet pressure.

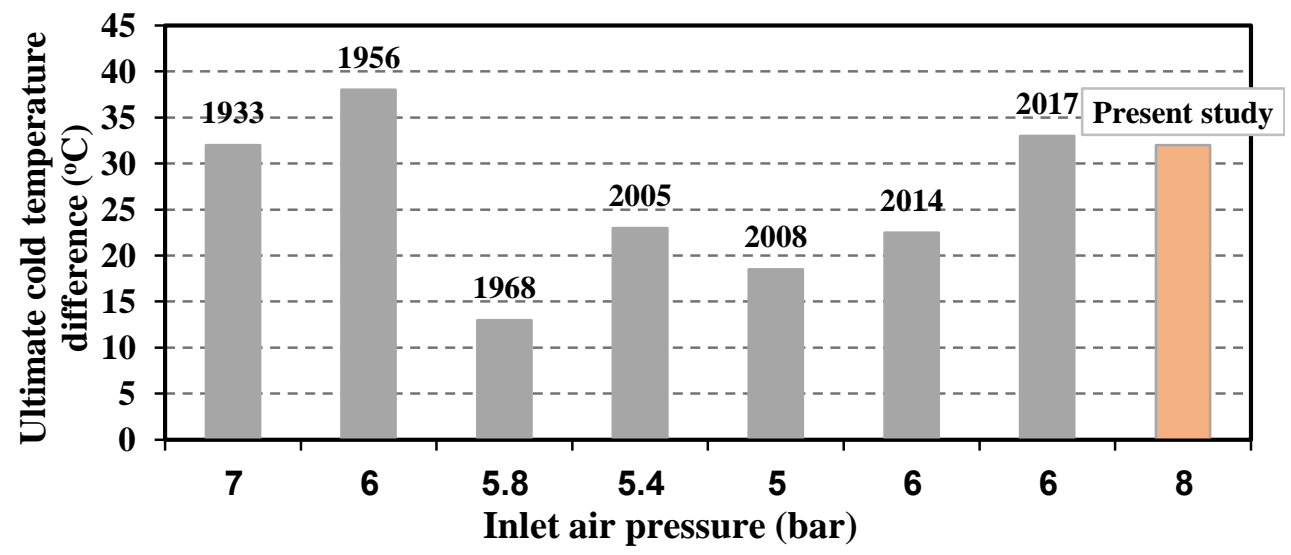

Fig. 11. Ultimate cold temperature difference versus inlet pressure. 


\section{Conclusions}

Characterizing the main properties of RHVT which is manufactured from aluminum material requires series of experiments to compare its performance with previous studies. The results of this paper are itemized below:

- It is clear that the primary effect parameter on temperature division in the VT is the inlet pressure. AS the maximum temperature separation could be recorded at extreme value of inlet pressures.

- The cold mass ratio is another effective parameter which governing the performance of the temperature division in the VT. The maximum values of the hot and cold temperature differences are founded at cold ratio of 0.4 and 0.9 , respectively.

- The cooling and heating COP values of this VT were affected by the cold mass fraction and its maximum values are 0.52 and 0.35 , respectively.

- From comparison results of temperature separation with most actual vortex tubes which have been used in some of previous researches; it was found that the tested vortex tube model enhances the heating temperature separation by $70 \%$ compared with other researches.

\section{References}

[1] R. G.J, "Experiments on expansion in a vortex with simultaneous exhaust of hot air and cold air", J. Phys. Radium, vol. 4, no. 7, pp. 112-114, 1933.

[2] R. G.J, "Method and apparatus for obtaining from alpha fluid under pressure two currents of fluids at different temperatures", U.S. Patent No. 1,952,281, Washington, DC: U.S. Patent and Trademark Office, 1934.

[3] H. R, "The use of the expansion of gases in a centrifugal field as cooling process", Review of Scientific Instruments, vol. 18, no. 2, pp. 108-113, 1947.

[4] E. S, W. K and P. P, "Experimental investigation on energy separation in a counter-flow Ranque-Hilsch vortex tube: Effect of cooling a hot tube", International communications in heat and mass transfer, vol. 37, no. 2, pp. 156-162, 2010.

[5] R. Westley, "Optimum design of a vortex tube for achieving large temperature drop ratios", Technical report no.30.Cranfield, UK: College of Aeronautics, 1955.

[6] T. H, "Studies on vortex tubes: (1) experiments on efficiency of energy separation: (2) on profiles of velocity and temperature", Bulletin of JSME, vol. 8, no. 31, pp. 433-440, 1965.

[7] T. H and S. N, "Studies on vortex tubes: 2nd Report, Reynolds Number. The Effects of the Cold Air Rate and the Partial Admission of Nozzle on the Energy Separation", Bulletin of JSME, vol. 9, no. 33, pp. 121-130, 1966.

[8] T. H and T. K, "Study on vortex tubes: effect of the bend of a vortex chamber on energy separation", Bulletin of JSME, vol. 17, no. 108, pp. 740-747, 1974.

[9] T. H and Y. H, "Energy separation in vortex tubes with a diver- gent chamber", ASMEJ Heat Transfer, vol. 103, pp. 196203., 1981.

[10] S. M.H and V. M.S, "Experimental modeling of vortex tube refrigerator", Applied Thermal Engineering, vol. 23, no. 15, pp. 1971-1980, 2003

[11] V. M.S and N. N, "Experimental modeling of a curved RanqueHilsch vortex tube refrigerator", International journal of refrigeration, vol. 34, no. 4, pp. 1109-1116, 2011.

[12] S. P.K, T. R.G, G. D and G. G.S, "An experimental performance evaluation of vortex tube", Journal of the Institution of Engineers (India), Part MC, Mechanical Engineering Division, vol. 84, pp. 149-153, 2004

[13] B. U et al., "CFD analysis and experimental investigations towards optimizing the parameters of Ranque-Hilsch vortex tube", International Journal of Heat and Mass Transfer, vol. 48, no. 10, pp. 1961-1973, 2005.

[14] A. M, A. H, A. M, S and E. A, A, "Experimental investigation for thermal performance of series and parallel Ranque-Hilsch vortex tube systems", Applied Thermal Engineering, vol. 123, pp. 327-339, 2017.

[15] K. H, U. O, K. E and K. V, "Experimental analysis of cooling and heating performance of serial and parallel connected counter-flow Ranquee-Hilsch vortex tube systems using carbon dioxide as a working fluid", . International Journal of Refrigeration, vol. 106, pp. 297-307.2019,

[16] S. S and S. M, "Review of Ranque-Hilsch vortex tube experiments using air", Renewable and sustainable energy reviews, vol. 52, pp. 172-178, 2015

[17] C. Gao, "Experimental study on the Ranque-Hilsch vortex tube", PhD Thesis, Technische Universiteit Eindhoven, 2005.

[18] M. V,S and A. V,P, "Investigation of the vortex thermal separation effect for gases and vapors", Soviet Physics-Technical Physics, vol. 1, no. 10, pp. 2233-2243, 1956.

[19] SLN. Vennos, "An experimental investigation of the gaseous vortex", PhD thesis, Rensselaer Polytechnic Institute, 1968.

[20] H. A, F, F. A and R. G, W, "Performance characteristics of a microscale Ranque-Hilsch vortex tube", Journal of fluids engineering, vol. 130, no. 10, 2008.

[21] D. K, Y. Y, B. A and B. S, "Experimental investigation of performance of hot cascade type Ranque-Hilsch vortex tube and exergy analysis", International journal of refrigeration, vol. 34, no. 4, pp. 1117-1124, 2011.

[22] D. K, "Experimental investigation of the effects of threefold type Ranque-Hilsch vortex tube and six cascade type Ranque-Hilsch vortex tube on the performance of counter flow Ranque-Hilsch vortex tubes.", International journal of refrigeration, vol. 34, no. 6, pp. 1366-1371, 2011.

[23] L. X and L. Z, "Investigation of the energy separation effect and flow mechanism inside a vortex tube", Applied Thermal Engineering, vol. 67, no. 1-2, pp. 494-506, 2014. 